\title{
Prevalence and prognosis of myocardial scar in patients with known or suspected coronary artery disease and normal wall motion
}

\author{
Rungroj Krittayaphong ${ }^{1 *}$, Pairash Saiviroonporn², Thananya Boonyasirinant ${ }^{1}$, Suthipol Udompunturak ${ }^{3}$
}

\begin{abstract}
Background: Some patients may have normal wall motion after myocardial infarction. The aim of this study was to determine the prevalence and prognosis of patients with myocardial scar in the absence of abnormal wall motion. We studied patients with suspected or known coronary artery disease (CAD) who were referred for cardiovascular magnetic resonance (CMR) for the assessment of global and regional cardiac function and late gadolinium enhancement (LGE) and had normal left ventricular wall motion. Prognostic value was determined by the occurrence of hard endpoints (cardiac death and nonfatal myocardial infarction) and major adverse cardiac events (MACE) which also included hospitalization due to unstable angina or heart failure or life threatening ventricular arrhythmia.
\end{abstract}

Results: A total 1148 patients (70.3\%) were studied. LGE was detected in 104 patients (9.1\%). Prevalence of LGE increased in patients with increased left ventricular mass. Average follow-up time was $955 \pm 542$ days. LGE was the strongest predictor for hard endpoints and MACE.

Conclusion: LGE was detected in 9.1\% of patients with suspected or known CAD and normal wall motion. LGE was the strongest predictor of significant cardiac events.

\section{Background}

Assessment of structural heart disease or ventricular function has been recommended for patients presenting with signs or symptoms of heart disease such as dyspnea on exertion, heart failure [1], chest pain or angina [2], and acute coronary syndrome [3]. Structural heart disease such as valvular heart disease and global or regional ventricular function is usually evaluated by echocardiography [1-3]. Left ventricular ejection fraction (LVEF) is one of the most important indices of global left ventricular function and wall motion abnormality represents regional myocardial function. The prevalence of myocardial infarction by clinical history may be underestimated since approximately $20-40 \%$ of myocardial infarction may be unrecognized $[4,5]$. The prognostic importance of late gadolinium enhancement (LGE) has been reported in many groups of patients such as coronary

\footnotetext{
* Correspondence: sirkt@mahidol.ac.th

'Division of Cardiology, Department of Medicine, Siriraj Hospital, Mahidol University, Bangkok, Thailand

Full list of author information is available at the end of the article
}

artery disease (CAD) [6], non-ischemic cardiomyopathy [7] and diabetic patients [8]. It has been shown that the presence $[6,8]$ and size [8] of myocardial scar and the presence of abnormal wall motion [8] had an impact on the prognosis of patients without clinical history of myocardial infarction. Little is known about the prevalence and prognosis of myocardial scar in patients with known or suspected CAD and normal wall motion.

Cardiovascular magnetic resonance (CMR) is considered the gold standard for the assessment of global ventricular function $[9,10]$ and a good tool for the assessment of regional ventricular function [11]. It also provides the data concerning myocardial scar, most commonly related to myocardial infarction, by LGE technique. This technique has been proven to be very accurate, comparable to histopathology [12], and have better accuracy than single photon emission computed tomography $[12,13]$, even in the setting of very small infarction [14], and it has also been shown to be highly reproducible [15].

The objectives of this study were 1) to determine prevalence of myocardial scar in patients with known or

\section{Biomed Central}


suspected CAD in the absence of abnormal wall motion and 2) to determine the prognostic value of myocardial scar in patients with known or suspected CAD in the absence of abnormal wall motion.

\section{Methods}

\section{Study population}

We studied patients who were referred for CMR from January 2002 to December 2007. Patients were referred for CMR due to clinical symptoms suspected to be related to CAD. Patients were included in this study if 1) known or suspected CAD who was referred for CMR for the evaluation of myocardial function and LGE 2) age more than 30 years and 3) normal left ventricular wall motion from CMR. Types of symptoms are shown in Table 1. Patients were excluded if any of the following criteria is presence: 1 ) had contraindication for CMR such as pacemaker or internal defibrillator implantation 2) history of myocardial infarction documented by standard criteria [16] 3) poor quality images for myocardial function or LGE 4) inability to complete CMR examination 5) history of revascularization 6) known disease that could cause LGE such as dilated cardiomyopathy [17], hypertrophic cardiomyopathy [18], myocarditis [19], cardiac amyloidosis [20] 7) clinically unstable conditions 8) need for urgent revascularization and 9) data unobtainable on clinical-follow-up. Since we excluded patients with history of myocardial infarction and history of revascularization, known CAD was defined as a history of at least $50 \%$ diameter stenosis of one or more major coronary arteries from coronary angiography who did not undergo revascularization and those with history of myocardial ischemia by nuclear study.

This study was approved by the Ethics committee of Siriraj Hospital. All patients provided written informed consent.

\section{CMR protocol}

All patients underwent CMR which included functional study and assessment of LGE using a 1.5 Tesla Gyroscan NT Philips scanner (Philip Medical System, Best, the Netherlands). After scout images, functional study was performed with a steady-state free-precession technique in horizontal long axis view, 2-chamber view, 4-chamber view and multiple slice short axis view. LGE was performed in 3-D fashion 7-10 minute after the injection of gadolinium $0.2 \mathrm{mmol} / \mathrm{kg}$. Multiple short-axis slices at the same level as the functional study, 2-chamber and 4-chamber view were acquired for LGE.

Parameters for functional images were as follows: repetition time/echo time/number of excitations $=3.7 /$ $1.8 / 2,390 \times 312 \mathrm{~mm}$ field of view, $256 \times 240$ matrix, $1.52 \times 1.21$ reconstruction pixel, $8 \mathrm{~mm}$ slice thickness, 70 degree flip angle. Typical temporal resolution was
Table 1 Baseline characteristics of patients with and without LGE. Values are numbers (percentages) unless otherwise stated.

\begin{tabular}{|c|c|c|c|c|}
\hline Characteristics & $\begin{array}{c}\text { All } \\
\mathrm{N}=1148\end{array}$ & $\begin{array}{c}\text { LGE } \\
\mathrm{N}=104\end{array}$ & $\begin{array}{c}\text { No LGE } \\
N=1044\end{array}$ & $\begin{array}{c}P \\
\text { Value }\end{array}$ \\
\hline Male & $481(41.9)$ & $66(63.5)$ & 415 (39.8) & $<0.001$ \\
\hline $\begin{array}{l}\text { Mean (SD) } \\
\text { age (years) }\end{array}$ & $64.6(11.3)$ & $64.9(12.5)$ & $64.6(11.2)$ & 0.817 \\
\hline Smoking & $148(12.9)$ & 19 (18.3) & $129(12.4)$ & 0.086 \\
\hline Hypercholesterolemia & 729 (63.5) & $77(74)$ & $652(62.5)$ & 0.019 \\
\hline Diabetes mellitus & 381 (33.2) & $40(38.5)$ & $341(32.7)$ & 0.231 \\
\hline Hypertension & $732(63.8)$ & $76(73.1)$ & $656(62.8)$ & 0.038 \\
\hline $\begin{array}{l}\text { History of dyspnea on } \\
\text { exertion }\end{array}$ & 477 (41.6) & $53(51)$ & $424(40.6)$ & 0.041 \\
\hline History of heart failure & $23(2)$ & $2(1.9)$ & $21(2)$ & 0.951 \\
\hline Presence of chest pain & $576(50.2)$ & $48(46.2)$ & $528(50.6)$ & 0.390 \\
\hline \multicolumn{5}{|l|}{ Medication } \\
\hline -Beta blockers & $487(42.4)$ & $48(46.2)$ & $439(42)$ & 0.419 \\
\hline $\begin{array}{l}\text {-Calcium channel } \\
\text { blockers }\end{array}$ & $288(25.1)$ & $21(20.2)$ & $267(25.6)$ & 0.227 \\
\hline -Nitrates & $284(24.7)$ & $27(26)$ & $257(24.6)$ & 0.762 \\
\hline -Aspirin/clopidogrel & $600(52.3)$ & $60(57.7)$ & $540(51.7)$ & 0.245 \\
\hline -ACEI/ARB & $334(29.1)$ & $40(38.5)$ & $294(28.2)$ & 0.027 \\
\hline -Statins & $541(47.1)$ & $59(56.7)$ & $482(46.2)$ & 0.040 \\
\hline Ml by ECG & $89(7.8)$ & $17(18.1)$ & $72(7.4)$ & $<0.001$ \\
\hline \multicolumn{5}{|l|}{$\begin{array}{l}\text { CMR variables in mean } \\
\text { (SD) }\end{array}$} \\
\hline -LVEF (\%) & $71.0(9.1)$ & $69.8(10.7)$ & $71.1(9.0)$ & 0.255 \\
\hline -LVEDVI $\left(\mathrm{ml} / \mathrm{m}^{2}\right)$ & $60.6(19.6)$ & $62.4(22.0)$ & $60.4(19.4)$ & 0.320 \\
\hline -LVESVI $\left(\mathrm{ml} / \mathrm{m}^{2}\right)$ & $18.6(14.1)$ & $20.5(17.7)$ & $18.4(13.7)$ & 0.258 \\
\hline -LVMASSI $\left(\mathrm{g} / \mathrm{m}^{2}\right)$ & $48.8(17.3)$ & $63.0(31.7)$ & $47.3(14.5)$ & $<0.001$ \\
\hline
\end{tabular}

LGE = late gadolinium enhancement, $\mathrm{MI}=$ myocardial infarction, $\mathrm{CMR}=$ cardiovascular magnetic resonance, $\mathrm{ACEI}=$ angiotensin converting enzyme inhibitors, $\mathrm{ARB}=$ angiotensin receptor blockers, $\mathrm{LVEF}=$ left ventricular ejection fraction, LVEDVI = left ventricular end-diastolic volume index, LVESVI = left ventricular end-systolic volume index, LVMASSI = left ventricular mass index

25-30 ms. The LGE images were acquired with the use of $3 \mathrm{D}$ segmented-gradient-echo inversion-recovery sequence with echo time 1.25 , repetition time $4.1,15$ degree flip angle, $303 \times 384 \mathrm{~mm}$ field of view, $240 \times$ 256 matrix, in-plane resolution $1.26 \times 1.5 \mathrm{~mm}$, slice thickness $8 \mathrm{~mm}$ and 1.5 Sensitivity encoding factor. The whole study for each patient took approximately 40 minutes. Patients had ECG performed on the same day before undergoing CMR. Myocardial infarction by ECG was defined by the standard criteria [16].

\section{Analysis of CMR}

The analysis was performed on the ViewForum workstation (Philip Medical System, Best, the Netherlands). Functional CMR data were analyzed for volume, mass and ejection fraction of the left ventricle. The software made an automatic detection of the endocardial and epicardial border of the left ventricle during diastole and endocardial detection for images during systole. Manual adjustment 
was performed by an experienced technician. The software then made calculations for left ventricular end-diastolic volume (LVEDV), left ventricular end-systolic volume (LVESV), left ventricular mass (LVMASS), and LVEF. Calculation of indices of LVEDV (LVEDVI), LVESV (LVESVI) and LVMASS (LVMASSI) was performed to adjust for body surface area. Intra- and interobserver variability presented as percentages of the mean of 2 repeated measurements averaged \pm standard deviations were $3 \pm 4 \%$ and 4 $\pm 4 \%$ for LVEDV, $4 \pm 5 \%$ and $6 \pm 6 \%$ for LVESV and $3 \pm$ $4 \%$ and $5 \pm 5 \%$ for LVMASS.

LGE was analyzed by visual estimation for the presence or absence of LGE and quantification of LGE. LGE was graded segmental extent of LGE as follows: $0=$ no scar, $1=1-25 \%, 2=26-50 \%, 3=51-75 \%$, and $4=76-100 \%$ of LGE areas in comparison to segmental myocardial areas. Analysis of myocardial segments was based on 17-segment models [21] with the exclusion of segment 17 from analysis. Slices was classified as basal segments when tips of mitral valve is visualized, midcavity segments when papillary muscles are visualized and apical segments when they are beyond papillary muscles but before the cavity ends [21]. Each of the basal and mid-cavity slices was divided into 6 segments and each of the apical slices was divided into 4 segments. Total scar size was derived from the summation of scar grading of all segments, divided by 4 times the total myocardial segments and calculated as percentages of scar in comparison with myocardium [12].

Analysis of wall motion was performed by visual assessment. Wall motion and LGE was assessed by 2 readers independently of the history. Disagreement was solved by a $3^{\text {rd }}$ reader. Regional wall motion was analyzed by the use of the 17-segment model proposed by the American Heart Association [21]. Wall motion of each myocardial segment was recorded as 5 -grade system as followed: $1=$ normal, 2 = hypokinesia, 3 = akinesia, or $4=$ dyskinesia. Intra- and interobserver agreement for the presence of a LGE area in our center were $\mathrm{k}=0.94, \mathrm{p}<0.001$ and $\mathrm{k}=0.97, \mathrm{p}<0.001$ respectively using a signal intensity threshold of more than 2 standard deviations above the signal intensity of a remote myocardial region. The cut off of 2 standard deviations has been used in many previous studies [6-8]. Visual detection for LGE has been shown to be in a good agreement with the conventional technique with $\mathrm{k}=0.952$, $\mathrm{p}<$ 0.001 [22]. For the presence of abnormal wall motion, intra- and interobserver agreement were $\mathrm{k}=0.95, \mathrm{p}$ $<0.001$ and $\mathrm{k}=0.93, \mathrm{p}<0.001$ respectively

\section{Clinical follow-up}

Primary outcomes include both hard cardiac events and major adverse cardiac events (MACE). Cardiac death and myocardial infarction were considered as hard cardiac events. MACE includes hard cardiac events and hospitalization due to unstable angina, heart failure or lifethreatening ventricular arrhythmia. Assessment of cardiac events was performed by the review of medical records and telephone interview followed by document confirmation.

\section{Statistical analysis}

Data were described as mean \pm standard deviation (SD) for continuous data and count (percentages) for categorical data. Independent-samples T-test was used for the comparison of continuous data. Comparisons of categorical data were made by the Chi-square test or Fisher exact test wherever appropriate. Cox-regression analysis was used for the assessment of predictors for clinical outcomes and was described as hazard ratio and 95\% confidence interval (CI). Kaplan-Meier analysis with logrank test was used for survival analysis with comparison of survival data between groups. A p-value of $\leq 0.05$ was considered significant.

\section{Results}

We excluded 248 patients with a history of revascularization, 252 patients with a history of myocardial infarction, 18 patients who were unable to complete CMR examination, 8 patients with inadequate image quality, 4 patients with pacemakers, 5 patients with unstable clinical conditions, 14 patients unobtainable clinical follow-up data, 10 patients with mid-wall or patchy scar likely to be nonischemia cardiomyopathy scar, 3 patients with scar at the insertion site of right ventricular free-wall likely to be related to hypertrophic cardiomyopathy, 2 patients with subepicardial scar likely to be related to myocarditis, and 1 patient with diffuse LGE likely to be related to amyloidosis. After the exclusion, total of 1148 patients with normal left ventricular wall motion were included in this study. Average age was $64.6 \pm 11.3$ years. LGE was detected in 104 patients (9.1\%). Table 1 shows baseline characteristics of patients with and without LGE. The following factors were associated with LGE: male gender, hypercholesterolemia, hypertension, a history of dyspnea on exertion, use of certain medications such as angiotensin converting enzyme inhibitor (ACEI) or angiotensin receptor blocker (ARB), and statin. There were 132 patients (11.5\%) who underwent coronary angiogram before CMR study. The results of coronary angiogram showed single vessel disease in 35 (27\%), 2-vessel disease in 32 (24\%), 3-vessel disease in $29(22 \%)$ and no significant CAD in 36 patients (27\%).

Comparisons of CMR functional parameters were performed (Table 1). There was no significant difference in LVEF between patients with and without LGE. LVMASS index was significantly greater in patients with LGE in comparison to those without LGE. We further explored the relation between increased LVMASS index and the presence of LGE by dividing LVMASS index into 4 quartile groups. The prevalence of LGE was only $2.8 \%$ 


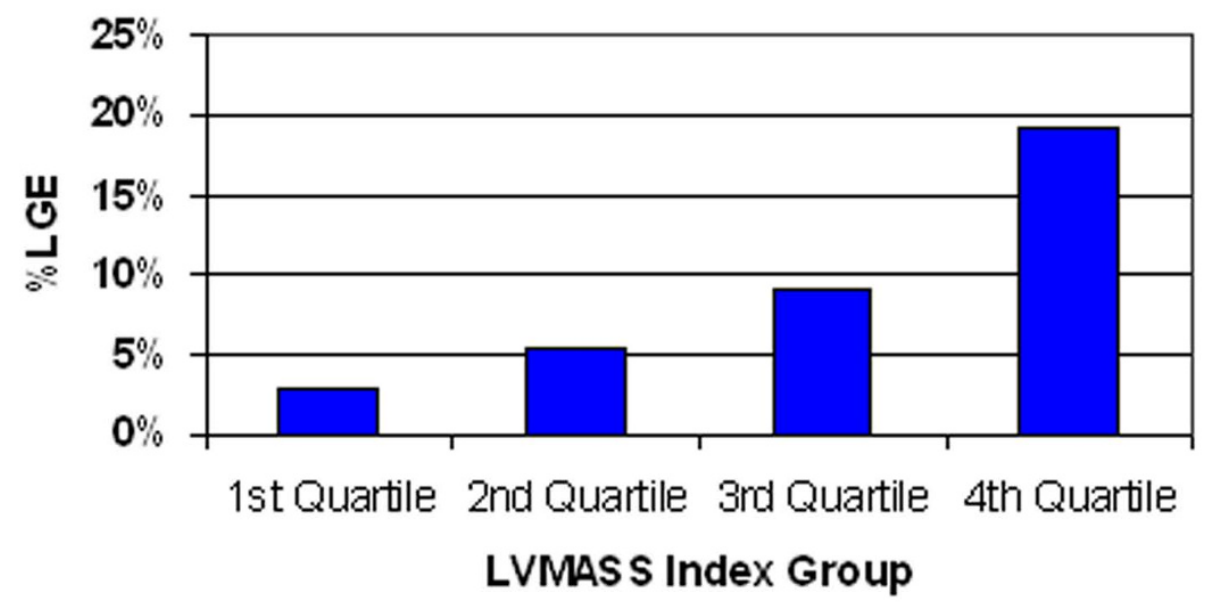

Figure 1 Percentages of LGE stratified by quartiles of LVMASS index

in the lowest quartile of LVMASS index group. The prevalence increased to $5.2 \%, 9.1 \%$ and $19.2 \%$ in the $2^{\text {nd }}, 3^{\text {rd }}$ and highest quartile respectively (Figure 1).

Coronary angiography data after CMR of those who had LGE was explored to confirm the underlying CAD in this group. Among 104 patients with LGE, 48 (46.2\%) underwent coronary angiography, 12 had single vessel disease, 15 had 2-vessel disease, 20 had 3-vessel disease, and only 1 patient had no significant CAD. Among those who underwent coronary angiography, 24 were in the highest quartile of LVMASS index, 13 in the $3^{\text {rd }}$ quartile, 4 in the $2^{\text {nd }}$ quartile and 7 in the lowest quartile. Figure 2 shows example of a patient with increased LVMASS index ( $3^{\text {rd }}$ quartile group) had LGE without abnormal wall motion. Among patients without LGE, coronary angiogram was performed in 145 patients (13.9\%) which demonstrated single vessel disease in 39, 2-vessel disease in 30, 3-vessel disease in 30, and no significant CAD in 46 patients.

\section{Predictors for cardiac events}

During an average follow-up time of $955 \pm 542$ days, 18 patients $(1.6 \%)$ had hard cardiac events and $54(4.7 \%)$ had MACE. The frequency of cardiac events is shown in Table 2. Univariate predictors and multivariable analysis for hard cardiac events and MACE were analyzed (Table 3 and 4). LGE is the only significant predictor for MACE and strongest predictor for hard cardiac event followed by myocardial infarction by ECG. However, as in Table 1 chance of having ECG evidence of myocardial infarction was small in patients with LGE. Besides, myocardial infarction diagnosed by ECG had a significant chance of false positive as it was noted in $7.4 \%$ of patients without LGE. Overall sensitivity, specificity, positive predictive value and negative predictive value of ECG evidence of myocardial infarction for the detection of LGE were $18.1 \%, 92.6 \%$, $19.1 \%$, and $92.1 \%$ respectively. Kaplan-Meier graph with log rank test of LGE as the predictor for hard cardiac events and MACE is shown in Figure 3. Since there may be a possibility that some patients may undergo coronary angiography or revascularization related to the results of CMR and had cardiac events caused by the procedures, we looked at the rate of cardiac events related to the procedures in both groups within 6 months after the CMR. Revascularization was performed in 28 patients (26.9\%) who had LGE and 79 patients who had no LGE (7.6\%).

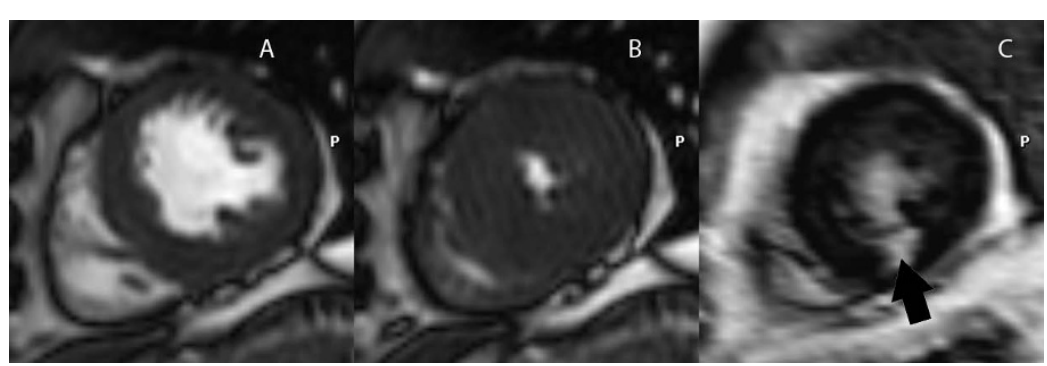

Figure 2 Functional images at diastole (A), systole (B) and LGE images (C) of a patient with LGE at inferior wall (black arrow), normal wall motion and increased left ventricular mass index. 
Table 2 Summary of clinical events during follow-up. Values are numbers (percentages).

\begin{tabular}{lc}
\hline Clinical events & Number (\%) \\
\hline Total death & $32(2.8)$ \\
Cardiac death & $5(0.4)$ \\
Myocardial infarction & $13(1.1)$ \\
Hospitalization due to heart failure & $21(1.8)$ \\
Hospitalization due to unstable angina & $26(2.3)$ \\
Life-threatening ventricular arrhythmia & $1(0.1)$ \\
Coronary angiogram & $172(15)$ \\
$\quad$-no significant coronary artery disease & $48(27.9)$ \\
$\quad$-significant coronary artery disease & $124(72.1)$ \\
$\quad$-single vessel disease & $44(35.5)$ \\
$\quad$-double vessel disease & $38(30.7)$ \\
$\quad$-triple vessel disease & $42(33.8)$ \\
Percutaneous coronary intervention & $77(6.7)$ \\
Coronary bypass surgery & $30(2.6)$ \\
\hline
\end{tabular}

There were a total of 5 patients who had MACE related to revascularization within 6 months after CMR: 1 in LGE group $(0.96 \%)$ and 4 in non-LGE group $(0.38 \%)$ which had no statistical significance $(\mathrm{p}=0.379)$.
Additional analysis was performed for the assessment of the prognostic importance of the extent of LGE. By using the median size of LGE of $6.25 \%$ of myocardium, we graded the extent of LGE into 3 groups: no LGE, LGE $\leq$ median and LGE > median. Hazard ratios and 95\%CI for hard cardiac events and MACE for patients with LGE $\leq$ median were 2.14 (0.28-16.53), $\mathrm{p}=0.467$ and 3.36 (1.32-8.55), $\mathrm{p}=$ 0.011 compared to those without LGE. Multivariable analysis showed that patients with LGE $\leq$ median had no significant increase in risk of hard events but had a significant increase in risk of MACE (hazard ratio 3.28, 95\%CI 1.29-8.37, $\mathrm{p}=$ $0.013)$ compared to those without LGE. For patients with LGE > median, hazard ratios for hard events and MACE were 8.59 (3.23-24.37), $\mathrm{p}<0.001$ and 4.69 (2.28-9.67), $\mathrm{p}<$ 0.001 compared to those without LGE. Multivariable analysis showed that patients with LGE > median had a significant increase in risk of hard events (hazard ratio 7.96, 95\% CI 2.34-27.09, $\mathrm{p}=0.001$ ) and MACE (hazard ratio 4.51, 95\%CI 2.19-9.30, $\mathrm{p}<0.001$ ) compared to those without LGE.

\section{Discussion}

The results of our study showed that in patients with known or suspected CAD and normal wall motion, 9.1\%

Table 3 Univariate predictors of hard endpoints and MACE

\begin{tabular}{|c|c|c|c|c|}
\hline Clinical characteristics & Cardiac Death or Nonfatal MI (N = 18-1.6\%) & P Value & $\begin{array}{c}\text { MACE } \\
(\mathrm{N}=54-4.7 \%)\end{array}$ & P Value \\
\hline Male & $1.42(0.56-23.57)$ & 0.460 & $1.13(0.66-1.93)$ & 0.655 \\
\hline Body mass index $>25 \mathrm{~kg} / \mathrm{m}^{2}$ & $0.25(0.08-0.77)$ & 0.016 & $0.72(0.42-1.22)$ & 0.220 \\
\hline Age (per 10 year increment) & $0.94(0.63-1.40)$ & 0.756 & $1.15(0.90-1.48)$ & 0.256 \\
\hline Smoking & $0.48(0.06-3.61)$ & 0.475 & $0.67(0.24-1.85)$ & 0.437 \\
\hline Hypercholesterolemia & $0.95(0.37-2.44)$ & 0.909 & $1.22(0.69-2.15)$ & 0.487 \\
\hline Diabetes mellitus & $1.058(0.62-4.00)$ & 0.335 & $2.01(1.18-3.42)$ & 0.010 \\
\hline Hypertension & $0.73(0.29-1.86)$ & 0.514 & $1.10(0.63-1.93)$ & 0.730 \\
\hline Prior chest pain & $0.30(0.10-0.90)$ & 0.032 & $0.84(0.49-1.44)$ & 0.523 \\
\hline Prior dyspnea & $0.95(0.37-2.46)$ & 0.922 & $0.82(0.47-1.43)$ & 0.473 \\
\hline Prior heart failure & $1.58(0.56-5.85)$ & 0.235 & $2.18(0.53-8.96)$ & 0.279 \\
\hline \multicolumn{5}{|l|}{ Medication } \\
\hline -Beta blockers & $0.38(0.13-1.17)$ & 0.092 & $0.93(0.54-1.61)$ & 0.805 \\
\hline -Calcium antagonist & $0.19(0.42-3.34)$ & 0.742 & $1.20(0.66-2.17)$ & 0.556 \\
\hline -Nitrates & $0.90(0.30-2.72)$ & 0.845 & $1.01(0.54-1.88)$ & 0.986 \\
\hline -Aspirin/clopidogrel & $0.60(0.23-1.52)$ & 0.274 & $1.02(0.60-1.73)$ & 0.954 \\
\hline -ACEI/ARB & $0.70(0.23-2.13)$ & 0.531 & $0.87(0.47-1.5)$ & 0.644 \\
\hline -Statins & $0.60(0.22-1.59)$ & 0.301 & $0.71(0.41-1.23)$ & 0.216 \\
\hline MI by ECG & $7.02(2.20-22.38)$ & 0.001 & $1.65(0.59-4.60)$ & 0.340 \\
\hline \multicolumn{5}{|l|}{ CMR variables } \\
\hline -presence of LGE & $5.74(2.15-15.33)$ & $<0.001$ & $4.12(2.23-7.57)$ & $<0.001$ \\
\hline -LVEF (per 10\% decrement) & $1.39(0.90-2.14)$ & 0.135 & $1.19(0.91-1.56)$ & 0.208 \\
\hline -LVEDVI & $1.007(1.000-1.014)$ & 0.041 & $1.006(1.000-1.011)$ & 0.038 \\
\hline -LVESVI & $1.012(1.001-1.024)$ & 0.040 & 1.009 (1.000-1.019) & 0.054 \\
\hline -LVMASS index (per quartile) & $2.57(1.36-6.45)$ & $<0.001$ & $2.11(1.27-5.56)$ & $<0.001$ \\
\hline
\end{tabular}

$\mathrm{MI}=$ myocardial infarction, $\mathrm{MACE}=$ major adverse cardiac event, $\mathrm{ACEI}=$ angiotensin converting enzyme inhibitors, $\mathrm{ARB}=$ angiotensin receptor blockers, $\mathrm{CMR}=$ cardiovascular magnetic resonance, LGE = late gadolinium enhancement, LVEF = left ventricular ejection fraction, LVEDVI = left ventricular end-diastolic volume index, LVESVI = left ventricular end-systolic volume index, LVMASSI = left ventricular mass index 
Table 4 Multivariable associations for hard endpoints and MACE

\begin{tabular}{llc}
\hline & HR $(\mathbf{9 5} \% \mathrm{Cl})$ & P Value \\
\hline $\begin{array}{l}\text { Cardiac death or nonfatal MI } \\
\quad \text { LGE }\end{array}$ & $5.43(1.71-17.25)$ & 0.004 \\
$\quad$-MI by ECG & $5.14(1.62-16.29)$ & 0.005 \\
MACE & & \\
$\quad$ LGE & $3.92(1.98-7.76)$ & $<0.001$ \\
\hline
\end{tabular}

MACE = major adverse cardiac event, $\mathrm{HR}=$ hazard ratio, $\mathrm{Cl}=$ confidence interval, $\mathrm{MI}=$ myocardial infarction, $\mathrm{LGE}=$ late gadolinium enhancement

had LGE. Patients with LGE had an increased risk of cardiovascular events compared to those without. In fact, LGE is the strongest predictor of cardiac events.

Echocardiography is an investigation for the evaluation of evidence of structural heart disease in patients with sign or symptoms of heart disease [1-3]. CMR, although of limited availability and more expensive, can assess evidence of structural heart disease to a greater extent than echocardiography $[17,18,20]$. Although echocardiography may have a better temporal resolution than CMR, the overall image quality of CMR for the assessment of regional wall motion is usually better than echocardiography $(11,23)$. In comparison with echocardiography, CMR has a better tissue contrast and better border definition thereby better endocardial detection. Image quality of echocardiography may also be compromised due to a poor acquisition window. CMR has been shown to be very accurate for the detection of myocardial scar [12] which may be related to a better image quality of CMR in comparison to echocardiography [9]. A previous study [5] showed that patients with unrecognized myocardial infarction diagnosed from ECG had regional wall motion abnormality, from echocardiogram, in $13 \%$ compared to $42 \%$ in those with recognized myocardial infarction. This may be due to the limited accuracy of ECG criteria for the diagnosis of myocardial infarction [4].

We showed that, among patients with normal wall motion, the prevalence of LGE increased in patients with high LVMASS index with the prevalence up to $19 \%$ in the highest quartile of LVMASS index. This finding is consistent with a previous report [5] which showed an increased LVMASS index from echocardiogram in patients with unrecognized myocardial infarction.

Compared to earlier report [6] on the prognostic importance of LGE in patients with known or suspected CAD, we focused on patients with normal wall motion which has not been reported before. We also had a larger number of patients with normal wall motion. Although they reported the findings of LGE and abnormal wall motion, the number of patients with normal wall motion in their study was small and cannot provide the prognostic data in this group. Calculation from the data that they reported, the prevalence of LGE in patients with normal wall motion was $7 \%$ which is slightly less than the prevalence in our study.

The results of this study on the prevalence of LGE and its prognostic value can be applied to patients who were referred for CMR with normal left ventricular wall motion without known cause of LGE. This is the reason that we excluded patients with history of myocardial infarction and other known causes of LGE including those with history of revascularization which may have a significant number of procedure-related LGE which was detected by CMR in up to $64 \%$ [14].

There are some limitations of this study. Firstly, although we exclude hypertrophic cardiomyopathy and many conditions that might cause LGE, we did not exclude left ventricular hypertrophy or aortic stenosis
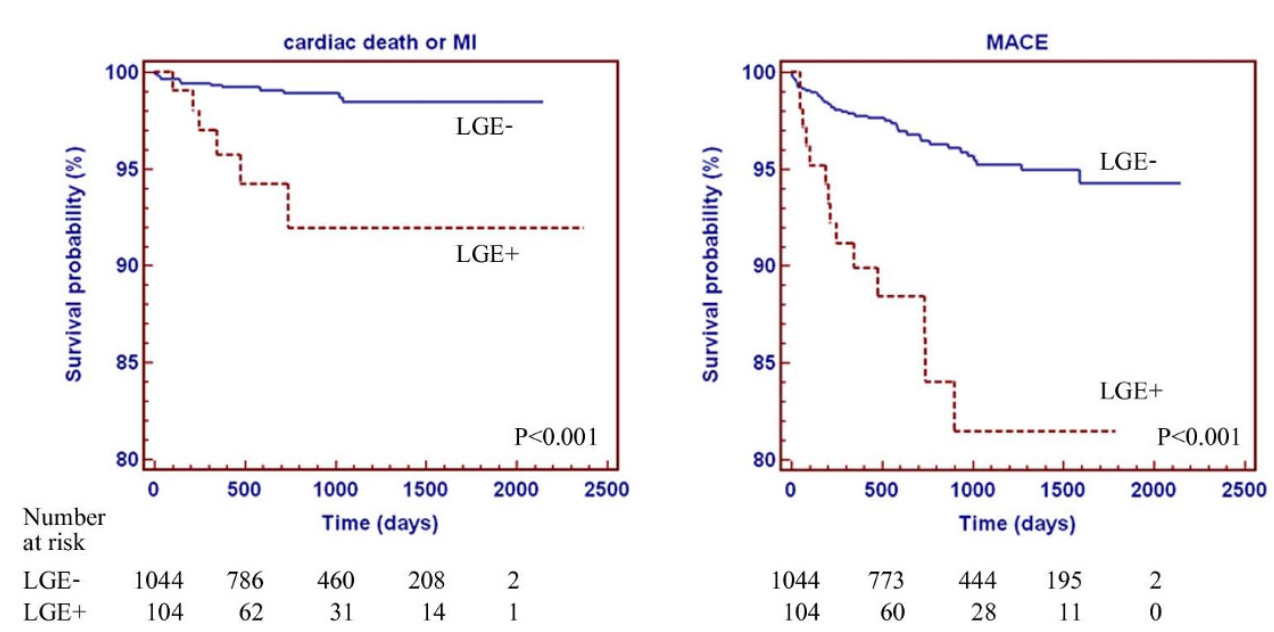

Figure 3 Kaplan-Meier graph of LGE and occurrence of hard cardiac events (left) and MACE (right). 
which has been shown to have an association with LGE [24]. However, in this study, we did not have any patients with severe aortic stenosis and LGE was an independent predictor after the adjustment of LVMASS. Secondly, the detection of abnormal wall motion was performed by visual assessment without the use of quantitative analysis although intra- and inter-observer agreements for wall motion assessment in our study were excellent as shown earlier. Lastly, this study did not analyze the influence of inducible wall motion abnormality or perfusion abnormality that might also have an effect on clinical outcome due to inadequate number of patients.

\section{Conclusion}

This is the first study that demonstrated the prognostic importance of LGE in patients with normal wall motion. The prognostic value of LGE in this patient population was even more confirmed by the quantitative analysis of LGE. Therefore, clinicians cannot assume that patients without wall motion abnormality have no evidence of structural heart disease and have a good prognosis. Although myocardial infarction by ECG was also an independent predictor for hard endpoints, LGE was the strongest predictor of hard endpoints and MACE.

\section{List of abbreviations}

ACEl: angiotensin converting enzyme inhibitor; ARB: angiotensin receptor blocker; CAD: coronary artery disease; Cl: confidence interval; CMR: cardiovascular magnetic resonance; HR: hazard ratio; LGE: late gadolinium enhancement; LVEDV: left ventricular end-diastolic volume; LVEDVI: left ventricular end-diastolic volume index; LVEF: left ventricular ejection fraction; LVMASS: left ventricular mass; LVMASSI: left ventricular mass index; LVESV: left ventricular end-systolic volume; LVESVI: left ventricular end-systolic volume index; MACE: major adverse cardiac event; MI: myocardial infarction, SD: standard deviation

\section{Acknowledgements}

The authors thank Ms. Supaporn Nakyen and Mr.Prajak Thanapiboonpol for the technical assistance of CMR scanning and analysis.

\section{Author details}

${ }^{1}$ Division of Cardiology, Department of Medicine, Siriraj Hospital, Mahidol University, Bangkok, Thailand. ²Department of Radiology, Siriraj Hospital, Mahidol University, Bangkok, Thailand. ${ }^{3}$ Department of Research Promotion, Siriraj Hospital, Mahidol University, Bangkok, Thailand.

\section{Authors' contributions}

RK study design, data interpretation, writing manuscript, PS data acquisition and interpretation, revise manuscript, TB data interpretation, revise manuscript, SU data analysis and interpretation, revise manuscript. All authors approved the final version of the manuscript.

\section{Competing interests}

The authors declare that they have no competing interests.

Received: 31 August 2010 Accepted: 6 January 2011 Published: 6 January 2011

\section{References}

1. Dickstein K, Cohen-Solal A, Filippatos G, McMurray JJ, Ponikowski P, PooleWilson PA, Stromberg A, van Veldhuisen DJ, Atar D, Hoes AW, Keren A,
Mebazaa A, Nieminen M, Priori SG, Swedberg K, Vahanian A, Camm J, De Caterina R, Dean V, Dickstein K, Filippatos G, Funck-Brentano C, Hellemans I, Kristensen SD, McGregor K, Sechtem U, Silber S, Tendera M, Widimsky P, Zamorano JL: ESC Guidelines for the diagnosis and treatment of acute and chronic heart failure 2008: the Task Force for the Diagnosis and Treatment of Acute and Chronic Heart Failure 2008 of the European Society of Cardiology. Developed in collaboration with the Heart Failure Association of the ESC (HFA) and endorsed by the European Society of Intensive Care Medicine (ESICM). Eur Heart J 2008, 29:29-2388.

2. Fraker TD, Fihn SD, Gibbons RJ, Abrams J, Chatterjee K, Daley J, Deedwania PC, Douglas JS, Ferguson TB, Gardin JM, O'Rourke RA, Williams SV, Smith SC, Jacobs AK, Adams CD, Anderson JL, Buller CE, Creager MA, Ettinger SM, Halperin JL, Hunt SA, Krumholz HM, Kushner FG, Lytle BW, Nishimura R, Page RL, Riegel B, Tarkington LG, Yancy CW: 2007 chronic angina focused update of the ACC/AHA 2002 guidelines for the management of patients with chronic stable angina: a report of the American College of Cardiology/American Heart Association Task Force on Practice Guidelines Writing Group to develop the focused update of the 2002 guidelines for the management of patients with chronic stable angina. J Am Coll Cardiol 2007, 50:50-2264.

3. Anderson JL, Adams CD, Antman EM, Bridges CR, Califf RM, Casey DE, Chavey WE, Fesmire FM, Hochman JS, Levin TN, Lincoff AM, Peterson ED, Theroux P, Wenger NK, Wright RS, Smith SC, Jacobs AK, Adams CD, Anderson JL, Antman EM, Halperin $J$, Hunt SA, Krumholz HM, Kushner FG, Lytle BW, Nishimura R, Ornato JP, Page RL, Riegel B: ACC/AHA 2007 guidelines for the management of patients with unstable angina/nonST-Elevation myocardial infarction: a report of the American College of Cardiology/American Heart Association Task Force on Practice Guidelines (Writing Committee to Revise the 2002 Guidelines for the Management of Patients With Unstable Angina/Non-ST-Elevation Myocardial Infarction) developed in collaboration with the American College of Emergency Physicians, the Society for Cardiovascular Angiography and Interventions, and the Society of Thoracic Surgeons endorsed by the American Association of Cardiovascular and Pulmonary Rehabilitation and the Society for Academic Emergency Medicine. J Am Coll Cardiol 2007, 50:e1-e157.

4. Barbier CE, Bjerner $T$, Johansson $L$, Lind L, Ahlstrom $H$ : Myocardial scars more frequent than expected: magnetic resonance imaging detects potential risk group. J Am Coll Cardiol 2006, 48:48-765.

5. Ammar KA, Samee S, Makwana R, Urban L, Mahoney DW, Kors JA, Redfield MM, Jacobsen S, Rodeheffer RJ: Echocardiographic characteristics of electrocardiographically unrecognized myocardial infarctions in a community population. Am J Cardiol 2005, 96:96-1069.

6. Kwong RY, Chan AK, Brown KA, Chan CW, Reynolds HG, Tsang S, Davis RB Impact of unrecognized myocardial scar detected by cardiac magnetic resonance imaging on event-free survival in patients presenting with signs or symptoms of coronary artery disease. Circulation 2006, 113:113-2733.

7. Wu KC, Weiss RG, Thiemann DR, Kitagawa K, Schmidt A, Dalal D, Lai S, Bluemke DA, Gerstenblith G, Marban E, Tomaselli GF, Lima JA: Late gadolinium enhancement by cardiovascular magnetic resonance heralds an adverse prognosis in nonischemic cardiomyopathy. J Am Coll Cardiol 2008, 51:51-2414.

8. Kwong RY, Sattar H, Wu H, Vorobiof G, Gandla V, Steel K, Siu S, Brown KA Incidence and prognostic implication of unrecognized myocardial scar characterized by cardiac magnetic resonance in diabetic patients without clinical evidence of myocardial infarction. Circulation 2008, 118:118-1011.

9. Grothues F, Moon JC, Bellenger NG, Smith GS, Klein HU, Pennell DJ: Interstudy reproducibility of right ventricular volumes, function, and mass with cardiovascular magnetic resonance. Am Heart J 2004, 147:147-218.

10. Bellenger NG, Burgess MI, Ray SG, Lahiri A, Coats AJ, Cleland JG, Pennell DJ: Comparison of left ventricular ejection fraction and volumes in heart failure by echocardiography, radionuclide ventriculography and cardiovascular magnetic resonance; are they interchangeable? Eur Heart J 2000, 21:21-1387.

11. Nagel E, Lehmkuhl HB, Bocksch W, Klein C, Vogel U, Frantz E, Ellmer A, Dreysse $\mathrm{S}$, Fleck E: Noninvasive diagnosis of ischemia-induced wall motion abnormalities with the use of high-dose dobutamine stress MRI: comparison with dobutamine stress echocardiography. Circulation 1999, 99:99-763. 
12. Wagner $A$, Mahrholdt $H$, Holly TA, Elliott MD, Regenfus M, Parker M, Klocke FJ, Bonow RO, Kim RJ, Judd RM: Contrast-enhanced MRI and routine single photon emission computed tomography (SPECT) perfusion imaging for detection of subendocardial myocardial infarcts: an imaging study. Lancet 2003, 361:361-374.

13. Ibrahim T, Bulow HP, Hackl T, Hornke M, Nekolla SG, Breuer M, Schomig A, Schwaiger M: Diagnostic value of contrast-enhanced magnetic resonance imaging and single-photon emission computed tomography for detection of myocardial necrosis early after acute myocardial infarction. J Am Coll Cardiol 2007, 49:49-208.

14. Ricciardi MJ, Wu E, Davidson CJ, Choi KM, Klocke FJ, Bonow RO, Judd RM, Kim RJ: Visualization of discrete microinfarction after percutaneous coronary intervention associated with mild creatine kinase-MB elevation. Circulation 2001, 103:103-2780.

15. Thiele H, Kappl MJ, Conradi S, Niebauer J, Hambrecht R, Schuler G: Reproducibility of chronic and acute infarct size measurement by delayed enhancement-magnetic resonance imaging. J Am Coll Cardiol 2006, 47:47-1641.

16. Alpert JS, Thygesen K, Antman E, Bassand JP: Myocardial infarction redefined-a consensus document of The Joint European Society of Cardiology/American College of Cardiology Committee for the redefinition of myocardial infarction. J Am Coll Cardiol 2000, 36:36-959.

17. McCrohon JA, Moon JC, Prasad SK, McKenna WJ, Lorenz CH, Coats AJ, Pennell DJ: Differentiation of heart failure related to dilated cardiomyopathy and coronary artery disease using gadoliniumenhanced cardiovascular magnetic resonance. Circulation 2003, 108:108-54.

18. Choudhury L, Mahrholdt H, Wagner A, Choi KM, Elliott MD, Klocke FJ, Bonow RO, Judd RM, Kim RJ: Myocardial scarring in asymptomatic or mildly symptomatic patients with hypertrophic cardiomyopathy. J Am Coll Cardiol 2002, 40:40-2156.

19. Mahrholdt H, Goedecke C, Wagner A, Meinhardt G, Athanasiadis A, Vogelsberg H, Fritz P, Klingel K, Kandolf R, Sechtem U: Cardiovascular magnetic resonance assessment of human myocarditis: a comparison to histology and molecular pathology. Circulation 2004, 109:109-1250.

20. Vogelsberg H, Mahrholdt H, Deluigi CC, Yilmaz A, Kispert EM, Greulich S, Klingel $K$, Kandolf $R$, Sechtem U: Cardiovascular magnetic resonance in clinically suspected cardiac amyloidosis: noninvasive imaging compared to endomyocardial biopsy. J Am Coll Cardiol 2008, 51:51-1022.

21. Cerqueira MD, Weissman NJ, Dilsizian V, Jacobs AK, Kaul S, Laskey WK, Pennell DJ, Rumberger JA, Ryan T, Verani MS: Standardized myocardial segmentation and nomenclature for tomographic imaging of the heart: a statement for healthcare professionals from the Cardiac Imaging Committee of the Council on Clinical Cardiology of the American Heart Association. Circulation 2002, 105:105-539.

22. Krittayaphong R, Saiviroonporn P, Boonyasirinant T, Nakyen S, Thanapiboonpol P, Udompunturak S: Accuracy of visual assessment in the detection and quantification of myocardial scar by delayedenhancement magnetic resonance imaging. J Med Assoc Thai 2007, 90(suppl 2):1-8.

23. Rickers C, Wilke NM, Jerosch-Herold M, Casey SA, Panse P, Panse N, Weil J, Zenovich AG, Maron BJ: Utility of cardiac magnetic resonance imaging in the diagnosis of hypertrophic cardiomyopathy. Circulation 2005, 112:112-855.

24. Rudolph A, Abdel-Aty H, Bohl S, Boye P, Zagrosek A, Dietz R, SchulzMenger J: Noninvasive detection of fibrosis applying contrast-enhanced cardiac magnetic resonance in different forms of left ventricular hypertrophy relation to remodeling. J Am Coll Cardiol 2009, 53:53-284.

doi:10.1186/1532-429X-13-2

Cite this article as: Krittayaphong et al:: Prevalence and prognosis of myocardial scar in patients with known or suspected coronary artery disease and normal wall motion. Journal of Cardiovascular Magnetic Resonance 2011 13:2. 